\title{
Quality as a part of modern technology in the automotive industry
}

\author{
Juraj Sinay $^{1}$, Štefan Markulik ${ }^{2}$, Hana Pačaiová ${ }^{3}$
}

\begin{abstract}
Automotive industry is not only represented by final manufacturers of the car make (referred to as OEMs), but the entire network of large and small suppliers who produce components for several automotive manufacturers. In order to implement this production according to customer requirements, they need to communicate with each other in a way and a language they can understand. This means specialist communication, its tools can be standards or standardized methodology to ensure quality throughout the production chain from the processing of raw materials to final assembly of the vehicle on the production line, its testing and the delivery to the customer. The basic precondition of Industry 4.0 strategy is communication in its broadest understanding. Communication or interconnection is conditioned by the application of generally accepted standards. Part of this connection is the focus on integrated management systems. Philosophy of Industry 4.0 is to minimize the risks as part of functional management systems. Timely and correct communication creates conditions for quality product at the end of the production and supply chain, i.e. a car according to customer requirements.
\end{abstract}

Keywords: quality; automotive industry; industry 4.0

\section{Introduction}

The automotive industry is currently one of the industries that are ready to integrate principles of the Industry 4.0 Strategy/Smart Industry within their structures. These are productive technologies which use automated systems, both in the production, as well as in the logistics chain. Meeting the requirements of customers during their purchase is part of a comprehensive information system that starts with receiving orders and continues by requesting the production in different parts of the world through Internet communication so that the final recipient gets the product at the agreed time and in the agreed quality.

Manufacturing technologies applied in automotive production traditionally, intensively and effectively apply quality management principles deriving not only

1 Automotive Industry Association of the Slovak Republic, Bojnická 3, 83104 Bratislava, Slovak Republic, email: juraj.sinay@tuke.sk

2 Technical University of Košice, Department of Safety and Quality Production, Faculty of Mechanical Engineering, Letná 9, 04200 Košice, Slovak Republic, email: stefan.markulik@tuke.sk 
from the standards, but also supporting effective methodologies for quality assurance in production.

\section{Structure of manufacturers in automotive industry}

Two principles of quality assurance are currently applied within the structure of the automotive industry, the so called American and German. American approach represents the methodology issued by the American Society for Quality (ASQ). German approach represents the methodology issued by the German Automotive Industry Association (VDA - Verband der Automobilindustrie). Despite the attempt to unify the requirements of the automotive industry, which led to the adoption of technical specification IATF 16949, some car manufacturers use the approach which they prefer.

All of these standards, methodologies, create mutual communication system throughout the supplier-customer system, from the processors of raw materials to final manufacturers (i.e. OEM - Original Equipment Manufacturer). In the automotive industry, the classification of suppliers (more precisely the degree of supplier-customer relations) uses well established manner of marking (Figure 1).

As nowadays there is no final car producer able to produce the whole car completely by themselves, they use external suppliers for the manufacture and supply of various components, which are divided as follows:

- Tier 1 - a group of external suppliers who supply their products directly to final car manufacturers. Essential requirement for this group (suppliers) is to provide their products by means of Just in Time (or Just in Sequence) system, i.e. always at the required time and at the appropriate place on the assembly line. In this regard, the geographic location (distance) to the car producer is the key factor.

- Tier 2 - a group of external suppliers who supply their products to the external suppliers in Tier 1 (i.e. sub-suppliers). Therefore, their customer is not OEM, but Tier 1.

- Tier 3 - a group of suppliers who deliver essential components,

- Tier 4 - a group of suppliers who supply raw materials (e.g. steel, glass, etc.).

An example for better understanding of supplier-customer relations:

- OEM - final car manufacturer,

- Tier 1 - seat manufacturer/supplier of seats for OEM,

- Tier 2 - XYZ (manufacturer of leather and textile lining)/supplier for Tier 1,

- Tier 3 - ABC (supplier of leather and textile)/supplier for Tier 2. 
Suppliers from Tier 2 and Tier 3 may not be located close to the OEMs, but they may be located throughout the territory (region, state). One external service may be categorized as Tier 1 for one (OEM) customers, but also may be categorized as Tier 2 for another (Tier 1) customer with another product.

\section{Smart industry or Strategy Industry 4.0}

Based on the structure of production technologies in the context of automotive production, it can be concluded that the conditions for the application of Industry 4.0 Strategy as a comprehensive philosophy are fulfilled, e.g. delivering final product (automobile) to the end customer according to their requirements. Implementation of this requirement has expanded communication level to all those working within the logistics chain. The resulting quality product can be achieved only when the same tools of quality management at all levels are applied in horizontal cross-linking of production and logistic structures. Based on the basic idea of the Industry 4.0 Strategy is the perception of the complexity of this philosophy, which involves all parts of the chain for the flow of information, linked to specific manufacturing and assembly workplaces. The final product delivered to the customer in accordance with the requirements encompasses several aspects. These are the fragments (areas) through which the philosophy of the strategy Industry 4.0 can be applied in the real production (Figure 2). The precondition of applying strategy Industry 4.0 is its functionality and the link between the individual areas. The areas shown in the figure below do not represent all areas. The application of the philosophy in practice will define other areas that are an essential prerequisite for the fulfilment of its objectives (Figure 2).

Research (development, innovation) 4.0 is an area essential for the company to develop in line with its sustainability and competitiveness. Therefore, the area of research is an important part of the strategy. Products in car manufacturing have a defined life, whether in terms of functionality or design. Car innovation time is about 6-8 years. OEMs must therefore continually develop their products and this imposes severe conditions for all participants in the production and logistics chain. To meet this market demand, applied research in new production technologies must developed in order to offer innovative products and maintain long-term customer favor and in-crease production efficiency.

Quality 4.0 focuses on the delivery of conforming product. This area involves the application of various tools and methods which are well established in the automotive industry and represent a kind of standardized basis - a precondition for the conformity of the product during its output from the process by means of their application.

Logistics 4.0 focuses on ensuring the appropriate supply of the process by input materials, in the right quality, quantity and time, as well as the supply of various 
production processes. Finally, it includes the distribution of the finished product (taking into account requirements) customer in the given amount and within given time.

Industry 4.0 strategy includes applications of information and communications technology methods that ensure effective communication - the exchange of information in real time, based on which the well-defined entry requirements (parameters) are applied to finished products that are provided to the customer in the right quantity, at the right quality at the right price, at the right time and to the right place. The precondition of reliable communication by means of adequate information and communications technology is a major challenge for effective and reliable communication within supplier-customer chain in order to streamline processes to meet the requirement on time of delivery and cost of the product for the customer with regard to their, maybe operationally changing, requirements.

Security 4.0 is an area that can be seen within "safety - security". In the context of "safety", i.e. occupational safety, the focus will be placed on flawless work of operators, where it is not possible to exclude the human factor from the process. Any accident can lengthen the time of delivery of the product or suspend its delivery completely. In the context of "Security," it is the protection of property, persons and information. Production machinery and equipment are in many cases complicated technological complexes, where any damage (e.g. sabotage) can have a liquidation effect for the manufacturer. The Industry 4.0 strategies are activities in relation to the Internet of Things, big data processing technologies and the use of cloud technology. In this regard, a strategic role is played by information security, failure of which may cause information noise or it may be subject to industrial espionage.

A new approach to quality management is based on risk. Each organization (manufacturer) will have to perform a risk analysis on their processes, to be able to define preventive measures to effectively prevent and thereby reduce the negative effects, but also identify area for possible opportunities. Risk analysis can become a strategic weapon in the competitive battle, because it can provide competition with vulnerabilities in processes or information about where the organization (manufacturer) perceives their opportunities.

Education 4.0 is an area that includes the preparation of competent staff for carrying out activities as part of the Industry 4.0 strategy. Most social systems face challenges to ensure sufficient capacity of qualified labor. In the Slovak Republic it is primarily due to the fact that the once successful model of dual education (profession-al/vocational) has gradually disappeared from the educational sys-tem. Therefore, the area of education as an integral part of the philosophy of Industry 4.0 is one of the priorities in the education process of a new, young, qualified and competent generation, which should meet the requirements of the labor market within the terms of Smart industry. Education is not a short-term activity, but a comprehensive strategic model of education beginning with preschool and ending at universities. Universities as educational and scientific institutions must work 
together so that the research and development in the automotive industry is an effective tool for its market competitiveness.

On the basis of Figure 2, it is clear that the above-described areas are not the only areas covered by the philosophy of Industry 4.0 strategy. There are far more areas that can be developed and linked with others with a focus on streamlining the entire supply chain. This can include such issues as, for example, automation (robotics), human resources management, maintenance, and environment and so on.

\section{Tools for implementing the Quality 4.0 in terms of the automotive industry}

One of the basic preconditions of Industry 4.0 strategy functionality is the already mentioned Internet of Things (IoT) and the mobility of data within it, preferably in real time (Figure 3). The scope and volume of data defining the communication between departments within the complex production and logistics systems as well as individual machines themselves, including robots with operators at various levels, is in such volume and such quality level of information that it's processing in digital form can only be carried out by Big Data technologies. These data are efficiently processed by cloud technology. This involves one of the distinctive aspects of modern production processes (based on widespread deployment of robots, automation systems within logistics operations - storage in modern warehouses or warehouses on wheels). The quality management systems must be applied to be compatible with the procedures previously applied within conventional manufacturing technology and logistics (handling flows). These processes stem from use of digital information. To obtain them, it is necessary to select locations for their collection, apply modern scanning equipment allowing digitization of signals and subsequently technologies for their subsequent mobility to customers via the Internet (Figure 3 ).

This fact conditions the application similarly as in the context of risk management systems, quality management systems (a new concept that has not been used yet, but is based on the principles of safety integration within the complex management systems) for all operations throughout the production chain of a car. System activities implementation within an integrated quality management system requires the application of both traditional and new tools for quality assurance.

These are difficult and complex production systems, as well as logistical approaches within the technical life of a final product (e.g. from planning, purchase of materials, processing, assembly, testing to the customer delivery) that are linked horizontally. An important role is played by the Just in Time requirement (or alternatively Just in Sequence) for supplies, which places high demands on the quality of communication flows in a broad sense (collection of relevant in-formation via machine interfaces, systems, people). In this context, various tools must be ap- 
plied (methods and methodologies for their application) as part of comprehensive quality management systems, or a development of procedures for the development of new tools and methodologies.

\section{Conclusions}

Digitalization, communication, information and/or its sharing are the main pillars of Industry 4.0 strategy as well as the key factors in the effort to deliver the finished product to the customer/product requirements and the required time. Due to the efficiency of production and logistics processes in the automotive industry, the management attention needs to focus on shortening production times, taking into account the minimization of losses in terms of production (e.g. the lack of inputs in the production process, industrial accidents, downtime due to failure within production technology, or a product at the output that does not conform with the product specification). Car manufacturers within the application Industry 4.0 strategy do not only focus on their production and the improvement of efficiency, but also on their customers and meeting their requirements for comfort when using the car. An example is the application of mobile phones, the application of which increases with the number of different applications, for example, Daimler AG has decided to develop a mobile application "Mercedes me" for owners of MercedesBenz vehicles [5]. It offers not only communication between the owner and the vehicle (which is typically the lock control, tire pressure, fluid levels, closing windows, etc.), it can also share information about technical condition with service centres and vice versa. Through monitoring of vehicle, the service centre can warn the driver of a hidden fault in the vehicle and call them to the service inspection and repair. Digitalisation is not a phenomenon anymore; it is common reality that should generally help humanity not only in work, but also the social aspects of life.

\section{Acknowledgement}

This contribution is the result of the project implementation APVV-15-0351 "Development and Application of a Risk Management Model in the Setting of Technological Systems in Compliance with Industry 4.0 Strategy".

This contribution is the result of the project implementation KEGA - 049TUKE 4/2014 "Designing a Model for E-learning Support of the Education in the Production Quality Bachelor Study Program“. 


\section{References}

[1] Studie Industrie 4.0 - Eine Standortbestimmung der Automobil - und Fertigungsindustrie, MHP A Porsche Company, 2014.

[2] Peichert, L.: Ohne qualität keine innovation, Best Practice, T-Systems, 2015, ISSN 1860-689X

[3] Jurina, L.: What comes after Industry 4.0, Visions, Siemens Bratislava, 2015, ISSN 1337-0014.

[4] Automotive Industry Association of the Slovak Republic. [Online][23.8.2016] http://www.zapsr.sk/.

[5] Daimler AG [Online][23.8.2016.] https://www.mercedes-benz.com/en/mercedes-me/. 
Figure 1. Structure of supplier

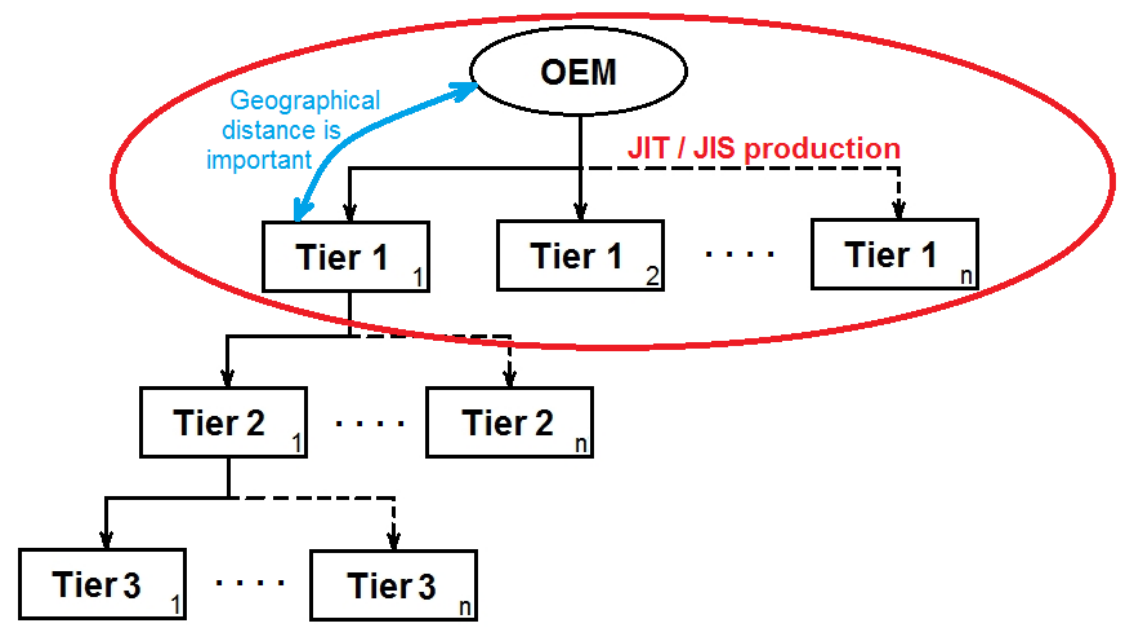

Figure 2. Understanding Philosophy of Strategy Industry 4.0

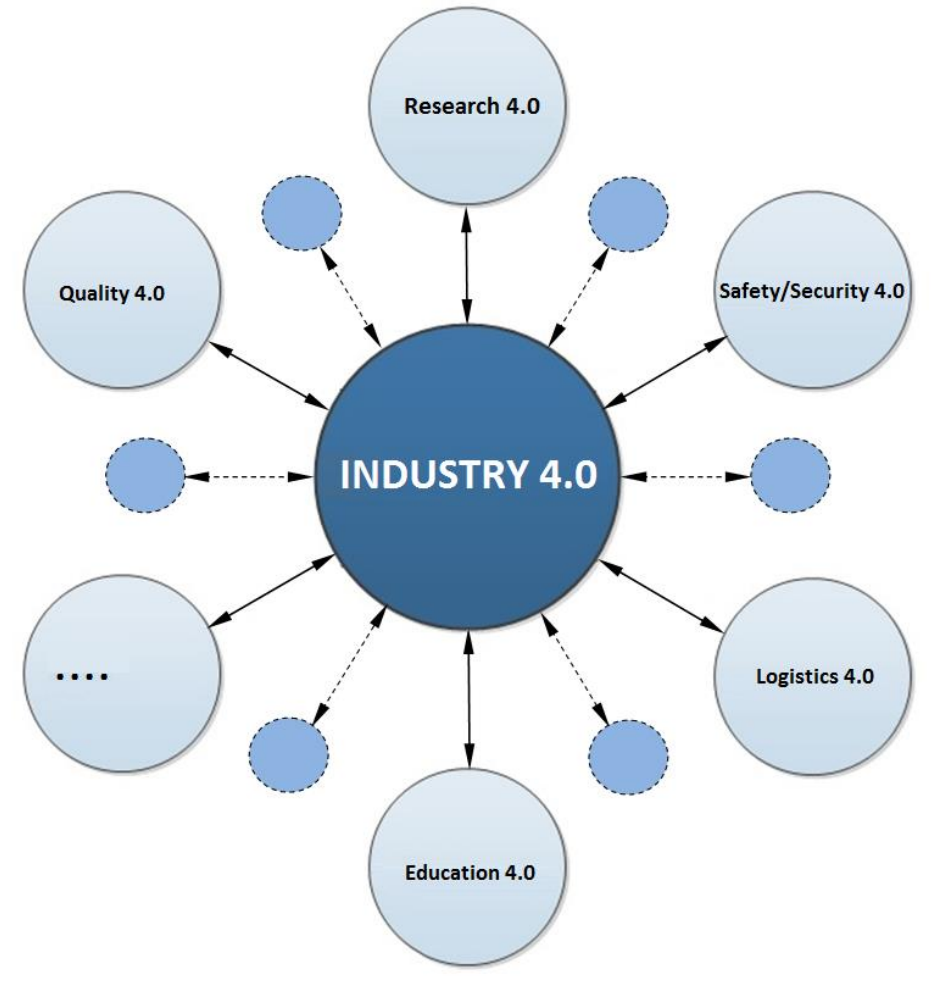


Figure 3. Principle of Strategy Industry 4.0

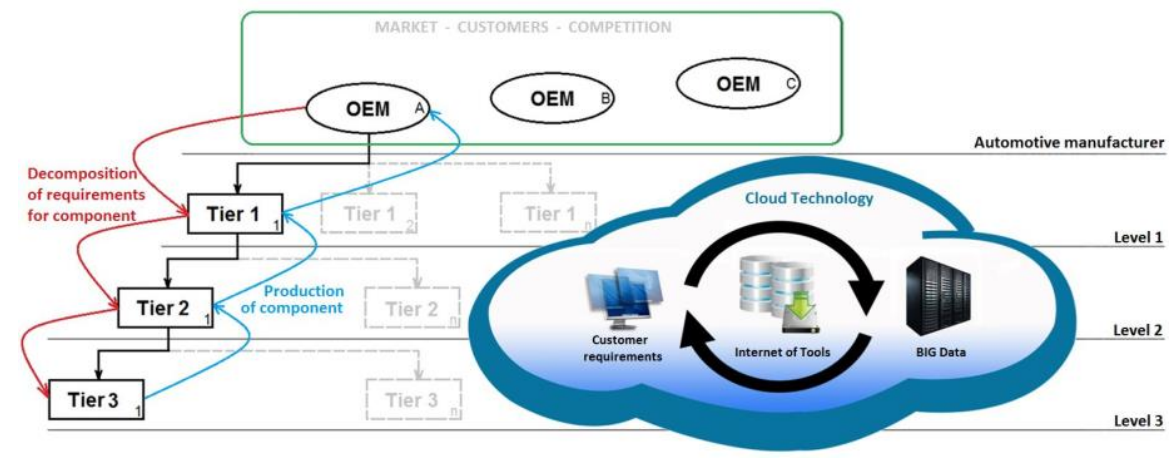

